Article

\title{
The Natural-Artificial Distinction and the Technologization of Sport
}

\author{
Aníbal Monasterio Astobiza
}

Miembro del Institute for Logic, Cognition, Language and Information, 20018 San Sebastian, Spain; anibalmastobiza@gmail.com

Received: 17 August 2020; Accepted: 1 October 2020; Published: 10 October 2020

check for updates

\begin{abstract}
The natural-artificial distinction is not only an abstract metaphysical question dedicated to classifying and differentiating between entities and phenomena that occur in nature from man-made objects. The distinction between the natural and the artificial is central to the philosophy of technology and an interesting heuristic to discuss important notions about the growing process of technologization in sport. For example, if one accepts the natural-artificial distinction, one is against any genetic intervention to improve sports performance because one would consider it unnatural. In this article, I present an argument against the natural-artificial distinction and defend the ethical permissibility of the technologization of sport.
\end{abstract}

Keywords: natural-artificial distinction; technology; sport; ethics

\section{Introduction}

The natural-artificial distinction is an old debate. It dates back to the fifth century B.C. For example, Aristotle 's Physics differentatiated between natural things and artifacts (physis and poiesis) and discuss the notion of craftmanship as an imitation of nature. For many, it is the first ethical debate in Western philosophy [1] (p. 675). The debate focused on the terms physis (nature) and nomos (culture): Do laws have a natural basis and you must obey them because that is how things are, or are laws a matter of convention and cultural tradition?

This first appearance of the antithesis between the natural and the artificial in the philosophical debate suggested questions about the meaning of "nature" and its role in ethics, the social origin of laws and the value of justice. Supporters of one or the other camp debated the distinction, while others tried to overcome and transcend the dichotomy. Nonetheless, the natural-artificial distinction itself is philosophically problematic. First and foremost, because it is very difficult to draw a line between the "natural" and the "artificial". The central thesis of this paper is that the natural-artificial distinction is untenable. If we translate this thesis to the field of sport, I want to argue that the common intuition about fair play in sport, that the use of certain technologies such as performance enhancing drugs, gene doping or robotic prosthesis are contrary to the sport ethos, is flawed because the underlying argument in support of the intuition fails. The intuition relies on a distinction between natural and artificial (technological) that is untenable and without the distinction, the argument cannot be constructed.

I am grateful to an anonymous reviewer for the suggestion to present the thesis with a simple and well known case to make it easier to understand my argument. Think of Lance Armstrong who won the Tour de France seven times in a row between 1999 and 2005. In 2012, he was accused of systematic doping by the United States Anti-Doping Agency and was stripped of all his titles and suspended for life. The vast majority of readers will find this action justified. But this action is only justified if you implicitly uphold the belief in the natural-artificial distinction.

This belief in the natural-artificial distinction is false as I will try to convince you in the following pages. The pieces of the argument seem scattered, or even the argument opaque at first sight, 
but progressively you will see how all pieces fit together perfectly. The third section presents the argument in a more formal way. Bear with me.

\subsection{Background: What Are Natural Entities?}

Modern physical sciences lack a clear concept of "nature" and natural objects. Even so, since Newton, physicists consider that what makes a situation "natural" is that it can be described in two parts: (1) the configuration of the system, characterizing its state in a particular time (t), and (2) the dynamic laws that govern its evolution [2]. It is very difficult for physicists to quantify the dynamic laws that govern the behavior of a system or situation, but whatever the ultimate constituents of the universe, it is assumed or believed that unlike artificial entities, natural entities and their behavior are not created by humans.

Natural entities have no function or at least physical theories do not make use of teleological concepts to describe natural entities. On the other hand, artificial objects have been created by technology to fulfill an instrumental function or practical purpose. Let's think about cars, bicycles, chairs ... However, artificial objects, as physical objects, ultimately obey physical laws. That is why they have a dual nature: as physical objects they do not have a teleological nature, but at the same time they condense a physical design thought by humans to fulfill a practical purpose.

In this sense, the natural-artificial distinction is ambiguous because the distinction is mainly genetic, say, of origin. In the design of an artificial object created by technology a practical reason is wanted to be fulfilled, but then this artificial object is placed in a causal network in relation to other natural entities, obeying the physical laws. On the other hand, it is very likely that the natural-artificial distinction does not take into account human beings as part of nature and at the same time as co-creators of his own nature or of their second nature: culture

\subsection{Sports (and Humans) as Autopoietic Systems Beyond the Natural-Artificial Distinction}

The human being is an autopoietic being, that is, she is a self-creating being. And there is no clearer activity than sport to observe the autopoiesis of the human being. The defining characteristic of an autopoietic system is its self-referentiality and sport is an example of an autopoietic system. Sport (or games) has an extremely self-referential character since it justifies and validates itself through modes, forms and conventions. In the words of Bernard Suits [3] (p. 148):

“... to engage in activity directed toward bringing about a specific state of affairs, using only means permitted by specific rules, where the means permitted by the rules are more limited in scope than they would be in the absence of the rules, and where the sole reason for accepting such limitation is to make possible such activity"

As can be seen in this definition of sport, sport is a world in itself, "a specific state of affairs", with sui generis rules. The rules of football (soccer for our American readers) and the standards by which excellence in football is judged, only make sense on the football pitch. The rules are arbitrary and irrelevant outside the world of football and even for other sports. And this leads us to the idea of autonomy that is central to understanding the autopoiesis of sport.

This definition of sport suggests that the rules of sport are conventional, constitutive rules that bar the players from making use of the most straightforward ways of achieving the goals. As such there is no compelLing reason for the arbiters to allow any enhancements that may be technologically feasible just because they are so. But the opposite is also true. Implicitly appeal to the natural-artificial distinction and consider that the use of technology such as performance enhancing drugs is bad or cheating, is not only based on a false distinction but goes against conventional nature of sport. Using technology is not allowed because the rules say so, not because there is a moral grounding or deeper rule to prohibit its use and when the technology in use does not cause any harm to the health of athletes there is no powerful reason to prevent the technologization of sport. 
Both the concept of autopoiesis and that of autonomy, in the sense used here, came from biology [4] and refer to the property of a system to reproduce, self-organize and maintain itself. In this sense, sport is a second-order autopoietic system, insofar as the human being is a born autopoietic being, who creates himself in an artificial way, and creator of other artificial systems that in turn are self-referential and interact with each other.

The nature of the artificial and the artificiality of the natural are therefore aspects to take into account when thinking about how certain social practices are constructed, sport for example, by the action of Homo Ludens. The co-construction between the natural and the artificial thanks to the marked autopoietic character of the human being and the emergence of second-order autopoietic systems, such as sport, reveal the false dichotomy between the natural and the artificial.

So, if the apparent natural-artificial distinction is not as such, if there is no truly genuine way to identify and differentiate that which is natural from that which is artificial: Why is this dichotomy so pervasive in sport?, why, when discussing the use of technology in sport, does the natural-artificial distinction underlie it?, why is sport identified with the natural and technology with the artificial?, why is natural good and artificial bad?

Some of these issues I will try to address them, as well as I can, in the following pages. In the next section, I will discuss some uses of technology in sport and what the moral implications are, and in the third section I will present an argument against the natural-artificial distinction to finally defend the process of technologization in sport in sections fourth and fifth, respectively.

\section{Use of Technology in Sport}

The technologization of sport is a dynamic and changing process. Technology is also a game changer in our understanding of sport. I will refer here to technology in a broad sense [5]. Because of this broadest sense of technology, skills and techniques of the body are technologies as well [6] (p. 175). Technology and skills of the body, both of them technologies and according to my reasoning natural, makes athletes overcome obstacles and reach new limits. But technology is not always welcome in sport and sometimes its use is prohibited. But this is a mistake. There are genetic differences that mirror the sorts of advantages given by the technologies in question. Given that we do not consider the genetic differences to be cheating, the technological versions should not either. Why are flexible pole, full body swimming suit or articulated speed skates -several types of technologies- allowed?, why are doping substances and/or performance enhancing biotechnology prohibited?

People are not comfortable with innovations that seem to go against what is considered natural and pose risks. Vaccines, organ transplants have been controversial in the past and to some extent today as well. Technology has always been considered unnatural. Technology as the set of skills, methods, processes ... that apply scientific knowledge in the form of machinery, equipment, instruments ... for practical purposes; is in itself a self-organizing or autopoietic system as economist Brian Arthur [7] reminds us.

This way of seeing technology as a system that organizes itself, perpetuates itself and adapts to the environment, has a "moral" or ultimate message. The growing technologization of society, but in particular the technologization of sport, is unstoppable. If technology resembles a living being one might think that technology does not need people. Technology has a status of its own and can control us. In this respect, let us consider the words of a philosopher of technology such as Martin Heidegger.

Martin Heidegger in his 1953 lecture in Munich entitled "Die frage nach der Technik" suggests that the essence of technique or technology is not technological. Martin Heidegger's work is often cited as a paradigmatic example of the philosophy of technology [5]. However, the philosophy of technology or technique of José Ortega y Gasset is just as far-reaching and influential as that of the German speaking philosopher [8]. According to Heidegger, technology is a way of looking at nature, of allowing all that is natural to reveal itself for human use. Ortega y Gasset [9] says something very similar: technology, or technique according to its terminology, is open to new possibilities for making human life. 
According to Ortega, thanks to technology we transform and adapt our environment by creating a second nature. If the human being is naked, thrown out in the open "natural-wildlife", technology allows him to dress himself and transform nature at will. Here again, we see the autopoietic character of the human being where the natural is artificialized and the artificial is naturalized.

For many, technology is nothing more than a pattern of nature that humans discover or innovate by putting it at their service. In a provocative article, Matt Ridley [10] says that technology leads to scientific discoveries and not the other way around as the relationship between science and technology is often thought to work (scientific discoveries lead to the development of new technologies, for example). Although Ridley has a political vision about how science should be financed, where state policies are not the only way to make science grow, the conception of technology that he maintains is clear: it is second nature or part of nature.

From this perspective, where the natural-artificial distinction has no place, if technology improves the nature of the athlete, what we are really talking about is nature transforming itself. Technology is not the opposite of nature, but an extension of it. If the natural-artificial distinction is maintained, the use of technology is always artificial and bad. In the following section I will present several uses of technology in sport and the moral challenges involved in maintaining the natural-artificial distinction as a valid premise.

\subsection{Prudential Use of Technology in Sport}

Nicholas Agar [11] (p. 2) makes a distinction between "prudentially rational" and "prudentially irrational" uses of technology and equates these two uses with "moderate enhancement" and "radical enhancement", respectively. López Frías [12] has applied this conceptual framework to sport to determine which technologies are permissible and which are not.

Agar's interest is not to assess the use of enhancement technologies in sport, but rather to position itself in the wider debate on the ethics of the use of technology for human enhancement. But López Frías [12] (p. 44) places it in the coordinates of sport and in particular in the internalist axiology of morally good values per se that prohibit the use of enhancement technologies in sport.

After an analysis of the limitations and strengths of Agar's approach, López Frías [12] (p. 49) concludes that -on the basis of the conceptual framework provided by Agar's approach- human enhancement technologies should only be prohibited in sport when: (a) the challenges that lie at the heart of sport disappear after the limitations in human capabilities are removed (enhancement) and (b) the effort that allows a true connection with the sport is eliminated and therefore the value placed on the athlete's performance when using the technology disappears.

The moral challenge of the prudential argument that Agar maintains around the use of technology for human enhancement, and that López Frías transfers to the microcosm of sport, is centered on considering that the experiences of those who use technology moderately will continue to be intelligible because they are not too meliorative so that non-enhanced beings do not feel that they exceed what is humanly possible.

That is, the prudential argument rests on the inconmensurability of values and experiences between enhanced and non-enhanced beings. Agar [13] (p. 12) calls it the "species-relativist argument" According to "species-relativist" argument, experiences that are valued by one species have no value for another species.

The "prudentially irrational" application of technology in sport, a technology that can produce athletes who exceed what is humanly possible, results in athletes and sports that we are unable to value because they are not what we expect or because the athletes are not like us. When I raise this gap between "them" and "us", between the enhanced and non-enhanced, I am talking about the different perception of the use of enhancement technology in sport among all actors in the world of sport: from fans, spectators, athletes, judges to referees, etc.

An audacious movement, not strictly focused on tackling the notion of "species relativism" -but on addressing a neglected aspect of the debate in philosophy and ethics of sport- is that of Søbirk 
and López Frías [14]. These authors highlight the asymmetry in the treatment given in the research literature to the use of enhancement technology (e.g., doping substances) for athletic performance, on the one hand, and enhancement technology (e.g., doping substances) for sport refereeing, on the other hand.

What if, in addition to the athletes, referees or judges will also use enhancement technology? I dare to add: What if the spectators and fans will also use enhancement technology? The extension of enhancement technology to all agents in the world of sport could resolve the incomparable experiences between enhanced and non-enhanced beings and offer a counter-argument to the prudential argument.

\subsection{Instrumental Use of Technology in Sport}

Technology in sport has multiple roles or functions. We can see technology in sport from an essentialist or constituent point of view, that is, without the ball in basketball it is not possible to play basketball or without the stick in hockey it is not possible to play hockey. But we can also see technology in sport from an instrumentalist perspective with the function of serving the interests, or the expression of an objective, of the people who play a sport.

A legitimate interest, and in line with the definition of sport given by Suits -where sport is defined as an activity governed by rules that mark a state of affairs- is to improve athletic performance. If sport is a state of affairs governed by rules that determine the activity itself, I dare to add that one of the essential characteristics of sport is not only to be a self-referential (autopoietic) and an autonomous system, but also an activity that challenges the limits of the human being.

Because of this definition of sport that challenges our limitations in order to overcome them and improve ourselves, technology from an instrumentalist sense is conductive to helping overcome such limitations. Basketball requires competition between two teams to pass the ball through a hoop as many times as possible. Passing the ball through the hoop requires motor skills and many other skills such as reasoning and strategic planning to prevent the other team from passing the ball through the hoop more times than your team.

A good shoe, padded, a sole with good traction to establish contact with the ground etc. is a technology to instrumentalize the goal of overcoming certain limitations in order to win in basketball.

\subsection{Trascendental Use of Technology in Sport}

Technology can be used in a prudential way as suggested by Agar's conceptual framework or in an instrumental way to achieve certain outcomes. And both types of uses occur in sport as we have seen above. But to continue with Agar's terminology, a prudentially irrational use can also be made in sport. A transcendental use of technology in sport would lead to transhumanist sport.

Transhumanism is the philosophical-political movement that seeks to overcome the cognitive, physical, emotional and moral limitations of the human condition through technology [15]. There are multiple variants of transhumanism [16], but two are paradigmatic: bioenhancement and cyberenchancement. The first is the improvement of our human condition through biotechnology. Advances in genetic engineering, synthetic biology etc. can facilitate the elimination of recessive genes and/or the manipulation and selection of genes responsible for socially perceived as good features.

The second variant of transhumanism, has as its ultimate goal the fusion between the machine and the human biological organism (cyborg). Great advances in neuroscience and applied technology (neurotechnology) have led to the creation of brain-computer interfaces that allow the control of external devices with thought (electrical activity of the brain) to facilitate communication and mobility of people with motor disorders.

Now let's imagine the application of these advances in biotechnology (bioenhancement) or Artificial Intelligence (cyberenhancement) in people without clinical symptoms, simply because of the desire to radically transform their basal condition. Let us also imagine the use of these technologies in sport to improve performance and overcome the unnecessary obstacles that the rules of sport determine must be overcome. Futurists and radical transhumanists dream of this future beyond natural abilities 
and wish for sports for transhumans. If we get to a transhumanist sport, as Professor José Luis Perez Triviño says, we will have to change the rules of fair play because the current ones will not be valid [17].

Athletes with bionic eyes capable of extreme precision for archery, bionic legs with biomechanics that result in speeds similar to cheetahs in a race or even weightlifting unimaginable without the aid of muscle-enhancing substances or exoskeletons, might be possible if there were no ban on the use of sports performance-enhancing technology or doping. The World Anti-Doping Agency [18] and other international bodies currently prohibit any type of doping method, whether technological, pharmacological or genetic, that enhances the performance of athletes. A transhuman sport, even if it were possible, would be unimaginable given the current consensus and status quo.

I consider that the current rules against doping are antithetical to the very essence and values of sport [18] and fall into multiple contradictions, but it is also ironic that natural cases of super-athletes or quasi- "transhumans" are calling into question the rules that prohibit the use of technology in sport to transcend the limits. For example, the middle-distance runner Caster Semenya probably has an intersex condition that causes her to produce very high levels of the hormone testosterone and her physiology and receptors for this hormone in her body are not those appropriate for a female athlete $(5 \mathrm{nMol} / \mathrm{L})$.

All rulings or decisions of the Court of Arbitration for Sport uphold the rules of World Athletics (formerly known as the International Association of Athletics Federations or IAAF) governing eligibility for athletic competition. From the point of view of this ruling, Caster Semenya is a man competing in a female category. But things are not that simple. Taking into account Semenya's biology, ethical reasoning shows how the ruling confuses sex with gender, discriminates against people with developmental disorders (hyperandrogenism) and is unfair [19].

Another natural case of an athlete with above-average characteristics that can be interpreted as an intermediate step to granting the possibility of transhumanist sport is that of the Finnish skier Eero Mäntyranta. Eero had a mutation that caused a high concentration of erythropoietin (EPO) and therefore had a large mass of red blood cells with the consequent effect of improving sports performance (EPO promotes the transport of oxygen to muscle tissues).

The cases of Caster Semenya and Eero Mäntyranta are natural occurrences of super-athletes (and they are not the only ones). When an athlete, because of a mutation or abnormal natural condition, does not fall within the categories established by sports agencies and committees, she is pointing out the arbitrariness of these rules. All these cases of athletes may seem unusual but they are natural. But let's think about height that is clearer example.

Height, is a phenotypic trait that has a genotypic cause. No one accuses tall basketball players of cheating simply because they are tall. Their unusual height is a great advantage in playing the game that derives from biological processes. If this biologically-based advantage is allowable, then biologically-based advantages are allowed. The question, as an anonymous reviewer has rightly pointed out, is: How can you who claim doping is cheating complain about those biological advantages that come out of an injection when you don't also complain about those that come from DNA?

The argument is that if we allow the natural-artificial distinction, then everything in sport is artificial, and therefore the line between slick swimsuits and performance enhancing drugs is merely arbitrary. If we allow shoes, eyeglasses, hockey sticks, ... then we allow for technology. Technology is technology and according to my argument technology is natural.

Someone can accuse me here of committing the continuum fallacy, insofar as there is no way of separating the natural from the artificial. That is, just because we cannot draw a sharp line anywhere along a continuum does not mean that there is no difference between the ends of the continuum, say, between allowing the use of technology (e.g., performance enhancing drugs) and not allowing the use of technology. The continuum fallacy is dissolved if the irrelevance of the natural-artificial distinction is defended and it is argued that everything is natural. 
Seeing technology as another dimension of nature, not accepting the natural-artificial distinction and understanding sport as an autopoietic system where its clear tendency is towards technologization, impels us to a transcendent use of technology.

\section{An Argument against the Natural-Artificial Distinction}

The natural-artificial distinction suffers from a tension between composition and counting, similar in many aspects to the theory of parthood relations -mereology [20] (p. 284). In this regard, if an object $\mathrm{x}$ is natural and has parts, classical mereology treats the parts as objects in the domain of quantification on a par with the object $x$ itself. But this seems counterintuitive because many natural objects have many parts that do not count as full-fledged objets themselves. This is because they are undetached or arbitrary designations of continuous matter: the neck of a giraffe or the eye of a dog.

\section{A Composionalist View against the Natural-Artificial Distinction}

The composionalist view says that seems perfectly natural to countenance wholes that are composed of two or more disconnected entities. According to W.V.O. Quine [21] a composite object is the aggregate content of any portion of space-time, however ragged and discontinuous. And they can be both natural and artificial composite objects. A bikini (man-made object) is one example and possibly the Earth and the Moon (natural system) is another.

Here I am not interested in dealing with the formal and logical relations of composition. About these aspects is classic Peter van Inwagen's book, Material Beings, that started a debate in the philosophical literature on composition. Here I want to present the compositionalist view as support to the idea of fusion, by which an object $x$, constitutively natural, and an object $y$, constitutively artificial, can merge and give rise to an object $\mathrm{z}$ that is not an artifact; but a natural thing.

This compositionalist view has four assumptions: (i) in the world there are natural and artificial objects, (ii) all objects both natural and artificial obey the physical laws of nature, (iii) natural objects and artificial objects can be merged together, then as all objects obey the physical laws of nature and they can be merged together (iv) the natural-artificial distinction is tautological, meaningless or unnecessary.

Keeping the explanatory presupposition implicit (iii), the argument can therefore be summarized in a simple manner in two premises and one conclusion.

Argument against the natural-artificial distinction:

(Premise 1): everything is part of nature and obeys its physical laws

(Premise 2): humans are part of nature, therefore everything they do is natural as well

\section{(Conclusion): the natural-artificial distinction is not correct}

At this point the questions we should ask ourselves are: (a) whether the argument is valid and (b) whether it is also solid, that is to say, whether in fact the premises are true, thus forcing the conclusion to be true as well. My intuition is that of course it's true and that the only relevant question concerns the most appropriate formulation of the argument. The key to the argument depends on the explanatory capacity of each of the assumptions considered (i), (ii), (iii), (iv) in accounting for the irrelevance of the natural-artificial distinction.

In short, this argument is highly intuitive and simple that seems irrefutable. However, some caveats can be made about the second premise. Artificiality does not have to be understood as an emerging property of the natural which leads to violation of the very core of this argument. As an anonymous reviewer noted we can think of related cases that seems to refute my argument. For example, the product of any unconscious system will lack consciousness. The brain is a set of unconscious atoms, therefore there can be no human consciousness. The problem with this type of reasoning is that it equates consciousness, on the other hand an entirely natural property, with 
artificiality. This suggests the fact that it can possibly emerge from something natural in the same way that consciousness emerges from unconscious phenomena. Might not artificiality emerge from the natural? It does not seem absurd. But the analogy breaks down when you realize that consciousness is natural and it emerges from natural processes and although it has parts that are not shared by its constituent parts; its parts are unfailingly natural tout court.

\section{What Is Natural in the Era of Technologization in Sport?}

"Natural" is an ambiguous philosophical term and it's not a very precise criterion to guide what's allowed or not allowed in sport. World Anti-Doping Agency prohibits any form of performance enhancement whether it be blood doping, illegal equipment, anabolic steroids etc. Almost all athletes are prohibited from using certain substances but others have therapeutic exemptions, so there's no proper standard to qualify what is natural or what is not.

If you try to understand "natural" as something biological you find yourself with borderline cases. For example, double-amputee sprinter Oscar Pistorius was disqualified from the Olympics in 2008 because Pistorius's prosthetic blades needed "less additional energy than running with natural limbs" and exhibited unique biomechanical characteristics that put athletes with natural legs at a disadvantage. The problem is that disqualifying athletes with non-biological characteristics is virtually impossible.

There aren't many athletes who haven't had an injury or surgery that places them with different "biological" abilities of what is originally natural. Similarly, there is no way to prove that a prosthesis is equivalent or not to a biological leg [22]. Therefore, "natural" is such an ambiguous term philosophically speaking that it should not be used by sports authorities as a rule.

With the growing process of technologization in sport (e.g., advances in biotechnology etc.) problems with defining "natural" will only increase. We can imagine a scenario where parents will select their children to be faster, stronger ... Will those children be able to compete in the Olympics?, this will go against the spirit of sport?

The allure of naturalnnes blinds us and has invaded virtually every context of our lives: from consumption, to the industry of wellness and even sport. Nature and natural is used as justification for anything that is believed to be right and good. We are very used to thinking that natural is good and unnatural bad. But as I have tried to argue throughout the article, unnaturalness is not a sign of dysfunction. Not only is the natural-artificial distinction irrelevant, but the unnatural does not explain what is outside the norm. Some natural systems are manifestly inferior to our so-called "artificial" systems [23]. Childbirth is one of those examples. Birth is dangerous, painful and difficult by nature [23] (p. 27). Young women are highly represented in the fossil record and from an evolutionary biology point of view childbirth is considered an example of non-intelligent design.

That's why technologically assisted childbirth is so much better than so-called natural childbirth. And the same can be said of sport. A sport with technology is no less good.

\section{Conclusions}

I have argued throughout this article that the natural-artificial distinction is a false dichotomy, pseudoproblem or ill-posed distinction and that technology is a dimension of nature rather than an artificial creation of human beings. These two premises applied to sport show us how the progressive technologization of sport is desirable and unstoppable [24]. We must reject the natural-artificial distinction [25] and understand that sport is an autopoietic system which impels us to a transcendental use of technology. The common intuition is that the use of technology is bad and goes against sport ethos because it is artificial. But the natural-artificial distinction, as shown by the argument above, is false. Therefore, technology use in sport cannot be bad. For this reason, and consequently, I believe is ethically permissible to use technology in sport. 
Funding: This work was supported in part by EXTEND (H2020 Research Project, ref. 779982), INBOTS (H2020, Research Project, ref. 780073), BIOethAI+ (FI2016-79000-P) and EthAI+3 (PID2019-104943RB-100).

Acknowledgments: The idea for this work derived from a suggestion by José Luis Perez Triviño. I thank him for trusting me.

Conflicts of Interest: The author declares no conflict of interest.

\section{References}

1. Hobbs, A. Physis and nomos. In Concise Routledge Encyclopedia of Philosophy; Craig, E., Ed.; Routledge: London, UK, 2000; p. 675.

2. Carroll, S. Is our universe natural? Nature 2006, 440, 1132-1136. [CrossRef] [PubMed]

3. Suits, B. What is a game? Philos. Sci. 1967, 34, 148-156. [CrossRef]

4. Varela, F.; Maturana, H.; Uribe, R. Autopoiesis: The organization of living systems, its characterization and a model. Curr. Mod. Biol. 1974, 5, 187-196. [CrossRef]

5. Coeckerlbergh, M. Introduction to Philosophy of Technology; Oxford University Press: Oxford, UK, 2020.

6. van Hilvoorde, I.; Vos, R.; de Wert, G. Flopping, Klapping and Gene Doping: Dichotomies Between "Natural" and "Artificial" in Elite Sport. Soc. Stud. Sci. 2007, 37, 2. [CrossRef]

7. Arthur, B. The Nature of Technology: What It Is and How It Evolves; Allen Lane: London, UK, 2009.

8. Diéguez, A.; Zamora Bonilla, J. Ortega, filósofo de la técnica. Estudio introductorio a la edición crítica del libro de José Ortega y Gasset. In Meditación de la Técnica y Ensimismamiento y Alteración; Biblioteca Nueva: Madrid, Spain, 2015.

9. Diéguez, A. La filosofía de la técnica de Ortega como guía para la acción. Una comparación con Heidegger. Rev. Int. Tecnol. Conoc. Soc. 2013, 2, 73-97.

10. Ridley, M. The Myth of Basic Science. Available online: https://www.wsj.com/articles/the-myth-of-basicscience-1445613954 (accessed on 14 May 2020).

11. Agar, N. Truly Human Enhancement: A Philosophical Defense of Limits; MIT Press: Cambridge, MA, USA, 2014.

12. López Frías, F.J. The use of performance-enhancing technologies in sports through NicolasAgar's "truly human enhancement" approach. Perform. Enhanc. Health 2018, 6, 44-52. [CrossRef]

13. Agar, N. Humanity's End: Why We Should Reject Radical Enhancement; MIT Press: Cambridge, MA, USA, 2010.

14. Søbirk Petersen, T.; López Frías, F.J. Promoting Fairness in Sport through Performance-enhancing Substances: An Argument for Why Sport Referees Ought to ‘Be on Drugs'. Sports Ethics Philos. 2020. [CrossRef]

15. Bostrom, N. What is Transhumanism? Available online: https://www.nickbostrom.com/old/transhumanism. html (accessed on 8 October 2020).

16. Diéguez, A. Transhumanismo: La Búsqueda Tecnológica del Mejoramiento Humano; Herder: Barcelona, Spain, 2017.

17. Triviño Perez, J.L. El deporte en una sociedad transhumanista y la necesidad de un fair play tecnológico. Mater. Hist. Deporte 2019, 19, 117-129.

18. WADA 2015 World Anti-Doping Code-Final Redlined to 2009 Code. Available online: https://www.wadaama.org/en/resources/the-code/world-anti-doping-code (accessed on 1 October 2020).

19. Savulescu, J. Ten Ethical Flaws in the Caster Semenya Decision on Intersex in Sport. The Conversation 2019. Available online: https://theconversation.com/ten-ethical-flaws-in-the-caster-semenya-decision-on-intersexin-sport-116448 (accessed on 10 May 2019).

20. Varzi, A. Mereological Commitments. Dialectica 2000, 54, 283-305. [CrossRef]

21. Quine, W. Whither Physical Objects? In Essays in Memory of Imre Lakatos; Cohen, R.S., Feyerabend, P.K., Wartofsky, M.W., Eds.; Springer: Berlin/Heidelberg, Germany, 1976; pp. 497-504.

22. Funken, J.; Willwacher, S.; Heinrich, K.; Müller, R.; Hobara, H.; Grabowski, A.M.; Potthast, W. Long jumpers with and without a transtibial amputation have different three-dimensional centre of mass and joint take-off step kinematics. R. Soc. Open Sci. 2019, 6, 190107. [CrossRef] [PubMed]

23. Levinovitz, A. Natural: How Faith in Nature's Goodness Leads to Harmful Fads, Unjust Laws, and Flawed Science; Beacon Press: New York, NY, USA, 2020. 
24. Monasterio Astobiza, A. ¿Es ético el uso de estimulación eléctrica del cerebro para acelerar el entrenamiento en habilidades, fuerza y rendimiento en el deporte? FairPlay Rev. Filos. Ética Derecho Deporte 2018, 11, $24-40$.

25. Tiles, M.; Oberdiek, H. Living in a Technological Culture: Humans Tools and Human Values; Routledge: London, UK, 1995. 